九州大学学術情報リポジトリ

Kyushu University Institutional Repository

TEN NEW SPECIES OF THE GENUS STYLOPS

(STREPSIPTERA, STYLOPIDAE) PARASITIC ON THE

GENUS ANDRENA (HYMENOPTERA, ANDRENIDAE) OF

JAPAN (Studies on the Japanese Strepsiptera XIII)

Kifune, Teiji

Maeta, Yasuo

https://doi.org/10.5109/2532

出版情報: ESAKIA. Special Issue 1, pp.97-110, 1990-04-20. Entomological Laboratory, Faculty of Agriculture, Kyushu University

バージョン :

権利関係: 


\title{
TEN NEW SPECIES OF THE GENUS STYLOPS (STREPSIPTERA, STYLOPIDAE) PARASITIC ON THE GENUS ANDRENA (HYMENOPTERA, ANDRENIDAE) OF JAPAN (Studies on the Japanese Strepsiptera XIII)
}

\author{
TEIJI KIFUNE \\ Department of Parasitology, School of Medicine, \\ Fukuoka University, Fukuoka, 814-01 Japan \\ and \\ YASUO MAETA \\ Division of Environmental Biology, Faculty of Agriculture, \\ Shimane University, Matsue, 690 Japan
}

\begin{abstract}
Ten new species of the genus Stylops (Strepsiptera, Stylopidae) are described from 11 species of the Japanese Andrena (Hymenoptera, Andrenidae). Those are : S. collinus sp. nov. from A. (Andrena) nawai, S. aburanae sp. nov. from A. (A.) aburana, S. dentatae sp. nov. from A. (Hoplandrena) dentata, S. aino sp. nov. from A. (H.) sachulinensis, S. orientis sp. nov. from A. (Gymnandrena) watasei, $S$. hirashimai sp. nov. from A. (G.) parathoracica, S. izumoensis sp. nov. from A. (Simandrena) opacifovea opacifovea, $\mathbf{S}$. nipponicus sp. nov. from A. (S.) nippon, S. montanus sp. nov. from A. (O reomelissa) mitakensis, S. subcircularis sp. nov. from A. (Mitsukuriella) japonica and A. (M.) fukaii. The male of S. yamatonis is described and many new localities are recorded on 7 known species such as S. japonicus, oblongulus, truncatoides, yamatonis, kaguyae, borealis, and valerianae. A. (Micrandrena) hikosana and A. (M.) komuchi are recorded as new hosts of S. kaguyae.
\end{abstract}

Notwithstanding the abundance of references on the Japanese Strepsiptera, only one paper by Kifune and Hirashima (1985) is contributable to the genus Stylops (Stylopidae) occurring in Japan. They described 9 new species on stylopized host specimens preserved in the Entomological Laboratory, Faculty of Agriculture, Kyushu University. As a continuation to it, we wish to describe other ten new species of Stylops from Japan based on our private collection.

The present materials were mainly collected by one of us (Y. M.) and our several friends. The parasites were extracted from their hosts, softened with $\mathrm{KOH}$ solution, and mounted with "NeoShigaral" (a commercial hydrophilic mounting medium). Descriptions are based on these mounted specimens. All of the holotypes are deposited in the above-mentioned Laboratory, and other specimens including some paratypes are tentatively preserved in our private collections to compare 
with other unidentified specimens in our hands.

\title{
Descriptions of New Species
}

\author{
Stylops collinus sp. nov. \\ (Nom. Jap. : Miyama-himehanabachi-nejirebane)
}

Female (Figs. 1 and 11)

Size. Cephalothorax $1.02 \mathrm{~mm}$ in length, $0.95 \mathrm{~mm}$ in maximum breadth at the spiracular level ; basal breadth at the constricted junction to abdomen $0.74 \mathrm{~mm}$; inter-mandibular distance $0.14 \mathrm{~mm}$.

Structure. Cephalothorax oblong; mouth transverse, elliptical ; mandible with a short but sharp tooth at the dorsal side of antero-interior angle ; spiracles located laterally, slightly protruded from the lateral margins; opening of brood chamber gently curved. Anterior margin of basal pigmented area gently curved ; anterior half of cephalothorax slightly pigmented but paler than basal band ; posterior margin of abdominal pigmented band slightly expanded posteriorly.

Host : Andrena (Andrena) nawai Cockerell.

Type Material: Holotype $q^{*}$ (Type No. 2776, Kyushu Univ.), extracted from a female host (4L †), Masutomi, Yamanashi, Honshu, 5. iv. 1962 (T. Saigusa) ; paratype $q$, extracted from another female (4R), Minamiminowa, Ina, Nagano, Honshu, 7. iv. 1961 (T. Kitamura).

OTHER SPECIMENS EXAMINED : 3 empty o -puparia from the same host as the holotype $\$(4 \mathrm{~L}, 4 \mathrm{R}$, $\& 4 \mathrm{R})$ and 1 empty d-puparium extracted from a female, same data as the holotype host.

REMARKs : The paratype $q$ is lacking left (right in the ventral view) mandible and slightly larger than the holotype. Pigmented area of anterior portion of cephalothorax is narrower than the latter. This new species is allied to S. japonicus from A. (A.) benefica but distinguishable by the broader pigmentation of cephalothorax and more remarkable mandibular teeth.

\section{Stylops aburanae sp. nov.}

(Nom. Jap. : Aburana-himehanabachi-nejirebane)

Female (Figs. 2 and 12)

Size. Cephalothorax $1.05 \mathrm{~mm}$ in length, $1.00 \mathrm{~mm}$ in maximum breadth at the spiracular level ; basal breadth at the constricted junction to abdomen $0.72 \mathrm{~mm}$; intermandibular distance $0.14 \mathrm{~mm}$.

Structure. Cephalothorax subtriangular ; anterior margin of mouth rounded, posterior margin almost transverse and straight; mandible with a sharp tooth at the dorsal side of antero-interior angle ; spiracles lateral, protruded from the lateral margins ; opening of brood chamber strongly curved. Anterior margin of basal pigmented area almost straight, remarkably darkened at the lateral extremities and along the posterior margin ; anterior half of cephalothorax slightly darkened but paler than basal band; posterior margin of abdominal pigmented area posteriorly expanded, almost triangular ; transverse pigmentation band visible in the middle of cephalothorax.

Host : Andrena (Andrena) aburana Hirashima.

TYPE MATERIAL : Holotype $\subsetneq$ (Type No. 2777 , Kyushu Univ.), extracted from a female host (4L), Todai, Ina, Nagano, Honshu, 15. iv. 1962 (K. Oshima).

OTHER SPECIMENS EXAMINED : 1 empty ơ -puparium extracted from a male host (4R), Minamimi-

* The symbols, or and $\%$, are used for the parasite only.

${ }^{\dagger}$ Parasitic position is indicated by the number of the metasomal tergite which covers the parasite. For example, $4 \mathrm{~L}, 4 \mathrm{R}, \& 4 \mathrm{R}$ mean that 3 stylopids are located between the 4 th and the 5 th metasomal segments, one at the left and other two at the right side. 
nowa, Ina, Nagano, Honshu, 13. iv. 1961 (Y. Maeta); and 2 empty ơ -puparia extracted from a male host (4L \& 4R), same locality, 11. iv. 1962 (Y. Maeta).

Remarks : This new species is allied to S. truncatoides from A. (A.) lapponica shirozui but distinguishable by the central pigmented area of cephalothorax and the larger mandibular teeth.

\section{Stylops dentatae sp. nov.}

(Togehoo-himehanabachi-nejirebane)

Female (Figs. 3 and 13)

Size. Cephalothorax $0.91 \mathrm{~mm}$ in length, $0.97 \mathrm{~mm}$ in maximum breadth at the spiracular level ; basal breadth at the junction to abdomen $0.74 \mathrm{~mm}$; intermandibular distance $0.15 \mathrm{~mm}$.

Structure. Cephalothorax trapezoidal, apex transverse ; lateral margins almost straight ; mouth with almost straight posterior margin, its anterior margin obscure ; mandible with a slightly outwardly directed small tooth at the dorsal side of the antero-interior angle; spiracles protruded from the lateral margins ; opening of brood chamber gently rounded. Pigmentation not so dark ; basal pigmented area short but its lateral extremities expanded to the spiracular level along the postspiracular lateral margins ; middle area of cephalothorax slightly pigmented ; pigmentation of abdomen paler than the basal band of cephalothorax.

Host : Andrena (Hoplandrena) dentata Smith.

TYPE MATERIaL : Holotype $\$$ (Type No. 2778 , Kyushu Univ.), extracted from a male host (4M), Todai, Nagano, Honshu, 29. iv. 1963 (Y.Maeta).

Remarks : Only one female specimen was discovered from the host species. This new species is characteristic in trapezoidal cephalothorax which is broader than long and less developed pigmentation.

\section{Stylops aino sp. nov.}

(Nom. Jap. : Aino-himehanabachi-nejirebane)

Female (Figs. 4 and 14)

Size. Cephalothorax $1.16 \mathrm{~mm}$ in length, $1.30 \mathrm{~mm}$ in maximum breadth at the spiracular level ; basal breadth at the junction to abdomen $1.02 \mathrm{~mm}$; intermandibular distance $0.18 \mathrm{~mm}$. Abdomen 2.00 $\mathrm{mm}$ or more in length, $1.15 \mathrm{~mm}$ in maximum breadth.

Structure. Cephalothorax subtrapezoidal, lateral margins gently curved, preoral margin rather slightly concave ; mouth transverse, elliptical ; mandible with a short triangular tooth at the anterointerior angle ; spiracles lateral, slightly protruded from the lateral margins; opening of brood chamber roundly curved, its lateral extremities slightly recurved inwardly. Basal pigmented area trapezoidal, peripheral area of cephalothorax pigmented broadly, but paler than the basal band ; basal pigmentation of abdomen as dark as the basal band.

Host : Andrena (Hoplandrena) sachalinensis Yasumatsu.

TYPE MATERIaL : Holotype $\$$ (Type No. 2779 , Kyushu Univ.), extracted from a male host (4R), Piuka, Teshio, Hokkaido, 21. vii. 1952 (T. Shirozu).

Remarks : Only one stylopized male of this host bee was obtained. This new species is characteristic in the large size of body, broadly pigmented peripheral portion of cephalothorax, and slightly concaved preoral margin. 
2000

000

000 

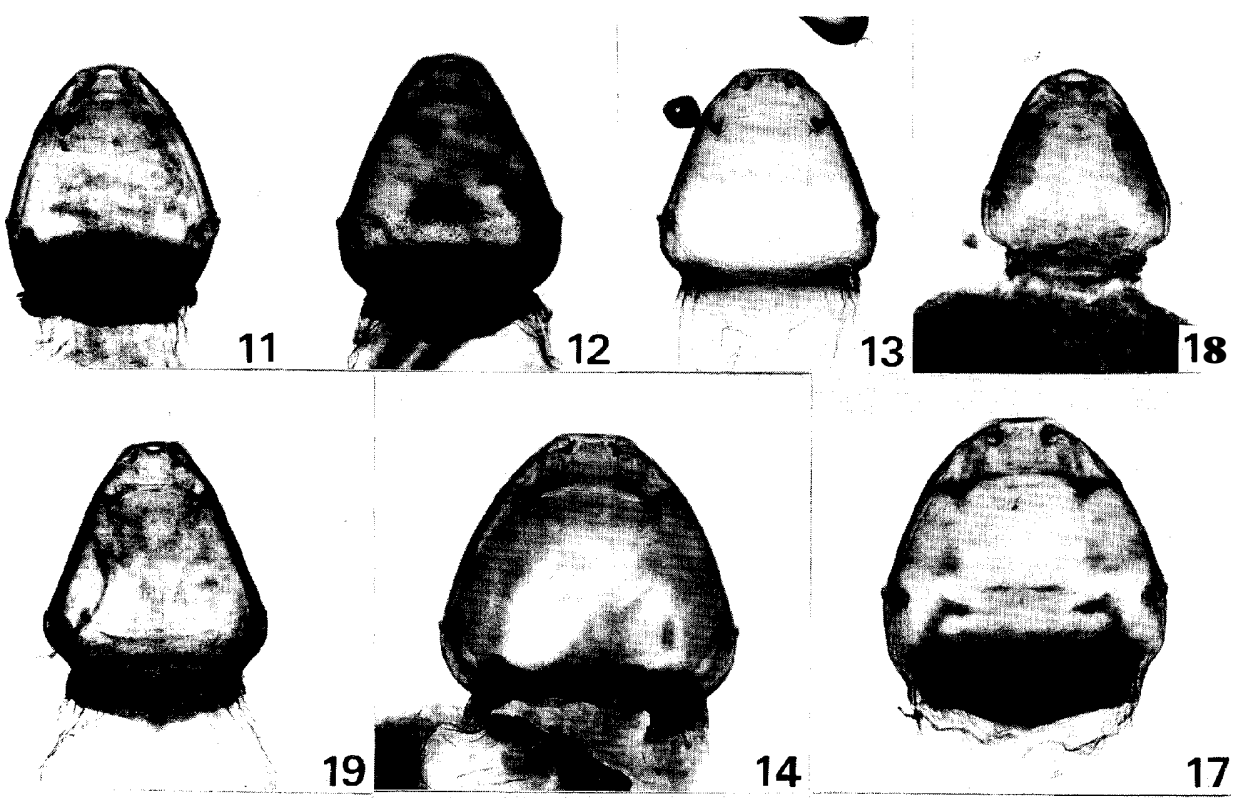

14
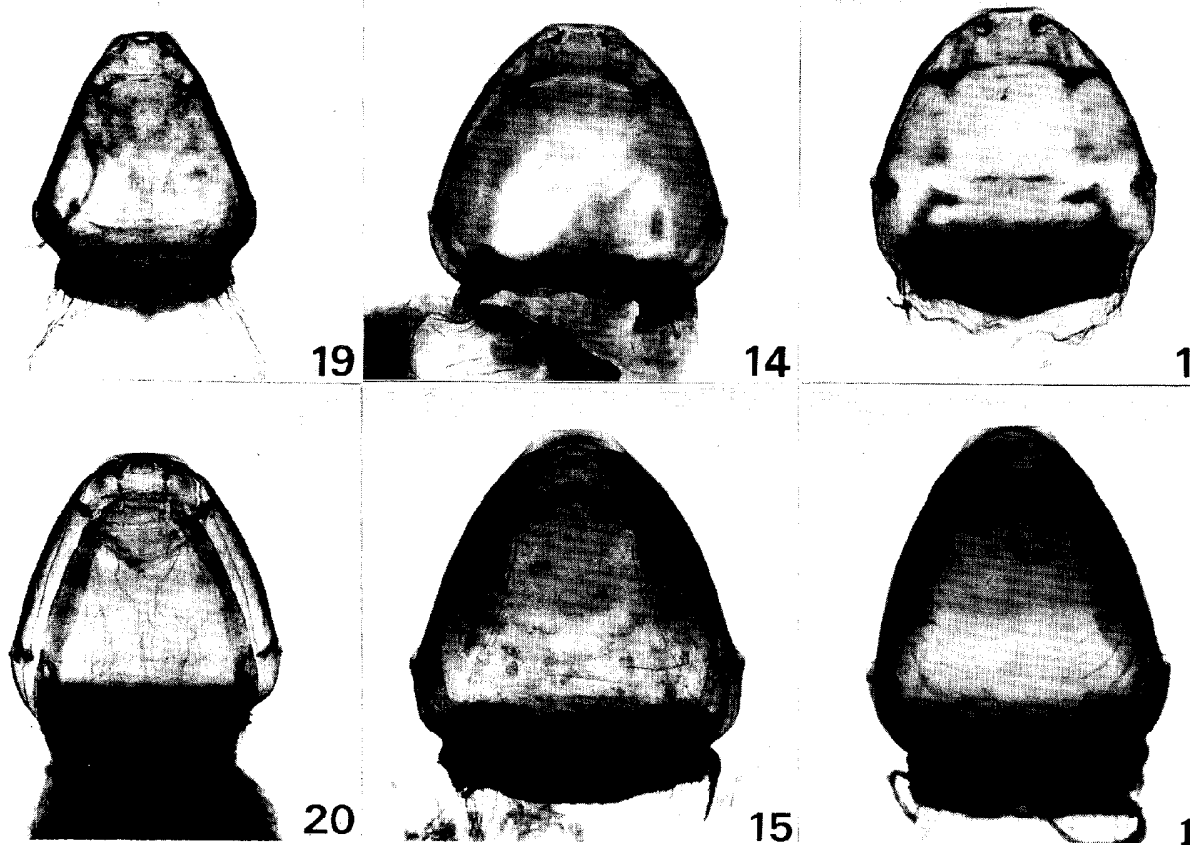

16

Figs. I-20. Female cephalothoraces of Stylops of Japan, ventral view.-1, 11, S. collinus sp. nov. from Andrena (Andrena) nawai ; 2, 12, S. aburanae sp. nov. from A. (A.) aburana ; 3, 13, S. dentatae sp. nov. from A. (Hoplandrena) dentata ; 4, 14, S. aino sp. nov. from A. (H.) sachalinensis ; 5, 15, S. orientis sp. nov. from A. (Gymnandrena) watasei ; 6, 16, S. hirashimai sp. nov. from A. (G.) parathor acica, 7, 17, S. izumoensis sp. nov. from A. (Simandrena) opacifovea opacifovea, 8, 18, S. nipponicus $\mathrm{sp}$. nov. from A. (S.) nippon; 9, 19, S. montanus sp. nov. from A. (O reomelissa) mitakensis ; 10, 20, $\mathbf{S}$. subcircularis sp. nov. from A. (Mitsukuriella) japonica. 1-10, Top, Enlargement of oral and mandibular portion ; bottom, total view. Scale, $1 \mathrm{~mm}$ for the bottom rows, $0.25 \mathrm{~mm}$ for the top rows.

\section{Stylops orientis sp. nov.}

(Nom. Jap. : Azuma-himehanabachi-nejirebane)

Female (Figs. 5 and 15)

Size. Cephalothorax $1.40 \mathrm{~mm}$ in length, $1.50 \mathrm{~mm}$ in maximum breadth at the spiracular level ; basal breadth at the abdominal junction $1.18 \mathrm{~mm}$; intermandibular distance $0.21 \mathrm{~mm}$. 
Structure. Cephalothorax subtriangular, preoral margin shortly transversely straight, lateral margins gently curved; mouth remote from the preoral margin, with rounded anterior and posterior margins; mandible also remote from the preoral margin, with a minute tooth at the antero-interior angle ; spiracles prominently protruded from the lateral margins ; postspiracular lateral margins of cephalothorax obtusely angled; opening of brood chamber gently curved. Basal pigmentation short ; almost all of anterior half of cephalothorax pigmented, its peripheral portion slightly darker than the median area ; posterior extremities of lateral pigmented area surpassing the spiracular area ; basal pigmentation of abdomen darker than the basal band.

Host : Andrena (Gymnandrena) watasei Cockerell.

TYPE MATERIAL : Holotype $\$$ (Type No. 2780, Kyushu Univ.), extracted from a female (4L), Nakamura-cho, Nerima-ku, Tokyo, Honshu, 5. v. 1952 (R. Ishikawa). Paratypes 2\%९, extracted from a female host (4L \& 4R), Hakodateyama, [Oshima,] Hokkaido, 10. v. 1955 (M. Munakata).

OtHER SPECIMENS EXAMined ; 19, extracted from a female host (4L), Mt. Bukka, Aiko, Kanagawa, 9. iv. $1954 ; 2$;, extracted from a male host (4L \& 4M), Nishikawatsu, Matsue City, 22. iv. 1982 (Y.Maeta); 1 stylopized female, Sotoyama, Iwate, Honshu, 8. vi. 1974 (Y. Maeta).

REMARKS : The specimen from Kanagawa is possessing more elongated cephalothorax and the two females from Matsue are much different in size to each other. The larger one of them is as large as the holotype.

\section{Stylops hirashinai sp. nov.}

(Nom. Jap.: Hirashima-himehanabachi-nejirebane)

Female (Figs. 6 and 16)

Size. Cephalothorax $1.44 \mathrm{~mm}$ in length, $1.33 \mathrm{~mm}$ in maximum breadth at the spiracular level ; basal breadth at the junction to abdomen $1.05 \mathrm{~mm}$; intermandibular distance $0.21 \mathrm{~mm}$.

Structure. Cephalothorax slightly oblong, apical margin truncated, lateral margins slightly curved, postspiracular lateral margins roundly curved ; mouth somewhat remote from the apical margin, with rounded posterior margin, its anterior margin obscure ; mandible with a small tooth at the antero-interior angle, its exterior margin undulated; spiracles protruded from the lateral margins; opening of brood chamber roundly curved. Basal pigmented area with slightly undulated anterior margin ; peripheral portion of cephalothorax slightly pigmented; anterior half of cephalothorax also colored, but paler ; basal pigmentation of abdomen darker, its posterior margin slightly expanded posteriorly and median portion slightly concave.

Host : Andrena (Gymnandrena) parathoracica Hirashima.

TYPE MATERIAL : Holotype $\$$ (Type No. 2781, Kyushu Univ.), extracted from a female host (4R), Nagae, Matsue, Honshu, 10. v. 1982 (Y. Maeta); paratype $\$$, extracted from another female host (4L), Honjo, Matsue, Honshu, 7. vi. 1981 (T. Nomura).

ANOTHER SPECIMEN EXAMINED ; 1 empty or-puparium extracted from the same female host as the paratype (4R).

Remarks : This new species is closely allied to S. orientis sp. nov. from A. (G.) watasei but differs from it by sharply truncated apical margin and more elongated shape of cephalothorax and short distance between apical margin and mouth.

\section{Stylops izumoensis sp. nov.}

(Nom. Jap. : Izumo-himehanabachi-nejirebane)

Female (Figs. 7 and 17) 
Size. Cephalothorax $1.18 \mathrm{~mm}$ in length, $1.25 \mathrm{~mm}$ in maximum breadth at the spiracular level ; basal breadth at the junction to abdomen $1.02 \mathrm{~mm}$; intermandibular distance $0.17 \mathrm{~mm}$.

Structure. Cephalothorax subpentagonal, apex trunctaed, its median portion slightly concave ; posterior margin of mouth curved, anterior margin obscure ; mandible subtriangular, with a blunt tooth at the antero-interior angle ; spiracles situated more anteriorly than in other species, protruded from lateral margins ; opening of brood chamber transversely straight, its lateral extremities slightly and obliquely bent backward. Basal pigmentation characteristic ; a pair of inwardly directed hookformed pigmentations visible at the lateral extremities of basal band ; anterior half of cephalothorax darkened but paler than the basal band ; pigmentation of basal abdominal segments as dark as the basal band and its posterior margin medially protruded posteriorly.

Host : Andrena (Simandrena) opacifovea opacifovea Hirashima.

TyPe MATERIal : Holotype $q$ (Type No. 2782 , Kyushu Univ.), extracted from a female host (4R), Mt. Makuragi, Shimane Pref., Honshu, 21. iv. 1983 (Y. Sasaki).

OTHER SPECIMENS EXAMINED : 2 stylopized female hosts, same locality as above, 7. vi. 1982 (Y. Maeta) ; 1 stylopized male, same locality as above, 16. iv. 1983 (Y. Maeta).

REMARKS : This new species is characteristic in unique pigmentation on the posterior half of cephalothorax and anteriorly situated spiracles. This is allied to S. dominiquei parasitic on $\mathbf{A}$. (Agandrena) agilissima and S. nassonowi from A. (Plastandrena) carbonaria in Europe but distinguishable from them by the anteriorly situated spiracles and slightly smaller size of cephalothorax.

\section{Stylops nipponicus sp. nov.}

(Nom. Jap. : Heriguro-himehanabachi-nejirebane)

Female (Figs. 8 and 18)

Size. Cephalothorax $0.84 \mathrm{~mm}$ in length, $0.82 \mathrm{~mm}$ in maximum breadth at the postspiracular level ; basal breadth at the abdominal junction $0.60 \mathrm{~mm}$; inter-mandibular distance $0.14 \mathrm{~mm}$.

Structure. Cephalothorax subtriangular with rounded angles, apical margin roundly expanded ; mouth with slightly undulating anterior and posterior margins; mandible with a small, triangular tooth at the antero-interior angle, its exterior margin undulated and surpassing the margin of cephalothorax ; spiracles almost unprotruded from the lateral margins ; opening of brood chamber with slightly curved margin of which lateral extremities strongly curved backwards. Peripheral area of lateral margins of cephalothorax most darkly pigmented, basal pigmented band paler, median portion of anterior half of cephalothorax slightly darkened, posterior half of it almost colorless ; pigmentation of basal abdominal segments also paler.

Host : Andrena (Simandrena) nippon Tadauchi et Hirashima.

TYPE MATERIAL : Holotype $\$$ (Type No. 2783 , Kyushu Univ.), gravid, extracted from a female host (4R), Shosenkyo, Yamanashi, Honshu, 6. iv. 1962 (Y. Maeta).

REMARKS : This new species is allied to $S$. yamatonis from A. (Simandrena) yamato but distinguishable by the smaller size of cephalothorax, unprotruding mouth, and remarkably undulating exterior margins of mandibles.

\section{Stylops montanus sp. nov.}

(Nom. Jap. : Yamate-himehanabachi-nejirebane)

Female (Figs. 9 and 19)

Size. Cephalothorax $1.03 \mathrm{~mm}$ in length, $0.95 \mathrm{~mm}$ in maximum breadth at the postspiracular level ; basal breadth at the abdominal junction $0.71 \mathrm{~mm}$; inter-mandibular distance $0.15 \mathrm{~mm}$. 
Structure. Cephalothorax almost hexagonal, remarkably oblong, apex trunctaed, lateral margins almost straight, broadest at a little posterior to the spiracles, postspiracular lateral margins obtusely angled ; mouth elliptical ; mandible surpassing the apical margin of cephalothorax, with a thick tooth at the antero-interior angle, its exterior margin slightly undulated ; opening of brood chamber with almost straight posterior margin and sharply, posteriorly directed lateral extremities. Basal pigmentation of cephalothorax moderate, anterior half of cephalothorax also moderately colored ; basal pigmentation of abdomen posteriorly expanded triangularly, darker than the basal band.

Host : Andrena (O reomelissa) mitakensis Hirashima.

TyPE MATERIAL : Holotype $\uparrow$ (Type No. 2784 , Kyushu Univ.), gravid, extracted from a female host (4R), Karuizawa, Nagano, 24. viii. 1950 (R. Ishikawa) ;1 paratype $\$$, extracted from a female host (4R), Yokoyama, Ina, Nagano, Honshu, 31. viii. 1962 (Y. Maeta).

OTHER SPECIMENS EXAMINED :10 -puparium (immature) extracted from the same host as the holotype (4R); 1 stylopized host, Mt. Asama, Kitasaku-dist., Nagano, Honshu, 27. viii. 1950 (R. Ishikawa).

REMARKS : This new species is characteristic in the oblong, subtriangular shape of cephalothorax and large mandibles. It is allied to S.oblongulus from A. (Andrena) longitibialis but distinguishable by the deficiency of anterior expansion of basal pigmented band of cephalothorax.

\section{Stylops subcircularis sp. nov.}

(Nom. Jap : Usuobi-himehanabachi-nejirebane)

Female (Figs. 10 and 20)

Size. Cephalothorax $1.20 \mathrm{~mm}$ in length, $1.19 \mathrm{~mm}$ in maximum breadth at the spiracular level ; basal breadth at the abdominal junction $0.79 \mathrm{~mm}$; intermandibular distance $0.16 \mathrm{~mm}$.

Structure. Cephalothorax oval, apex truncated, lateral and postspiracular margins gently curved ; mouth situated very nearly to the apical margin, transverse ; mandible small, with a short tooth at the antero-interior angle ; spiracles slightly protruded from the lateral margins ; opening of brood chamber gently curved. Anterior half of cephalothorax slightly darkened ; anterior margin of basal pigmented area almost transversely straight ; basal pigmentation of abdomen as dark as that of basal band, posterior margin of it slightly undulated.

Hosts : Andrena (Mitsukuriella) japonica (Smith) and A. (M.) fukaii Cockerell.

Type MATERIAL : Holotype $q$ (Type No. 2785 , Kyushu Univ.), extracted from a male of japonica (4R), Habiro, Ina, Nagano, Honshu, 31. vii. 1962 (Y. Maeta) ; paratype $\$$ from a female of fukaii (4L), Minamiminowa, Ina, Nagano, 6. iv. 1961 (Y. Maeta); paratypes 3 † from 3 females of fukaii (4L, 4L, \&4R), same locality, 7. iv. 1961 (T. Kitamura); paratype , same locality, 13. iv. 1961 (Y.Maeta).

OTHER SPECIMENS EXAMINED : 2 empty ơ-puparia extracted from 2 males of fukaii (4L \& 4L), same locality as the paratypes, 6. iv. 1961 (Y. Maeta) ; 1 empty ơ -puparium extracted from a female of fukaii (4L), same locality, 7. iv. 1961 (T. Kitamura) ; 1 stylopized male and 1 stylopized female of fukaï, same locality and same date (Y. Maeta); 1 stylopized male of fukaii, same locality, 11. iv. 1961 (Y. Maeta) ; 2 stylopized females of fukaii, same locality, 20. iv. 1961 (Y. Maeta); 1 q extracted from a male of fukaii (4R), Onoaida, Yakushima Is., Kagoshima, Kyushu, 26. iii. 1963 (K. Oshima) ;19 extracted from a male of japonica (4R), Minamiminowa, Ina, Nagano, 16. vii. 1963 (Y. Maeta); 19 on a male of japonica (4R), Nishikawatsu, Matsue, Shimane, 12. iv. 1984 (Y. Maeta).

REMARKS ; This is closely allied to S. circularis from A. (Gymnandrena) sasakii but differs from it by the undulating exterior margins of the mandibles and the shortly truncated apex of cephalothorax. The sole specimen from Yakushima Is., which is excluded from the type material, is slightly 

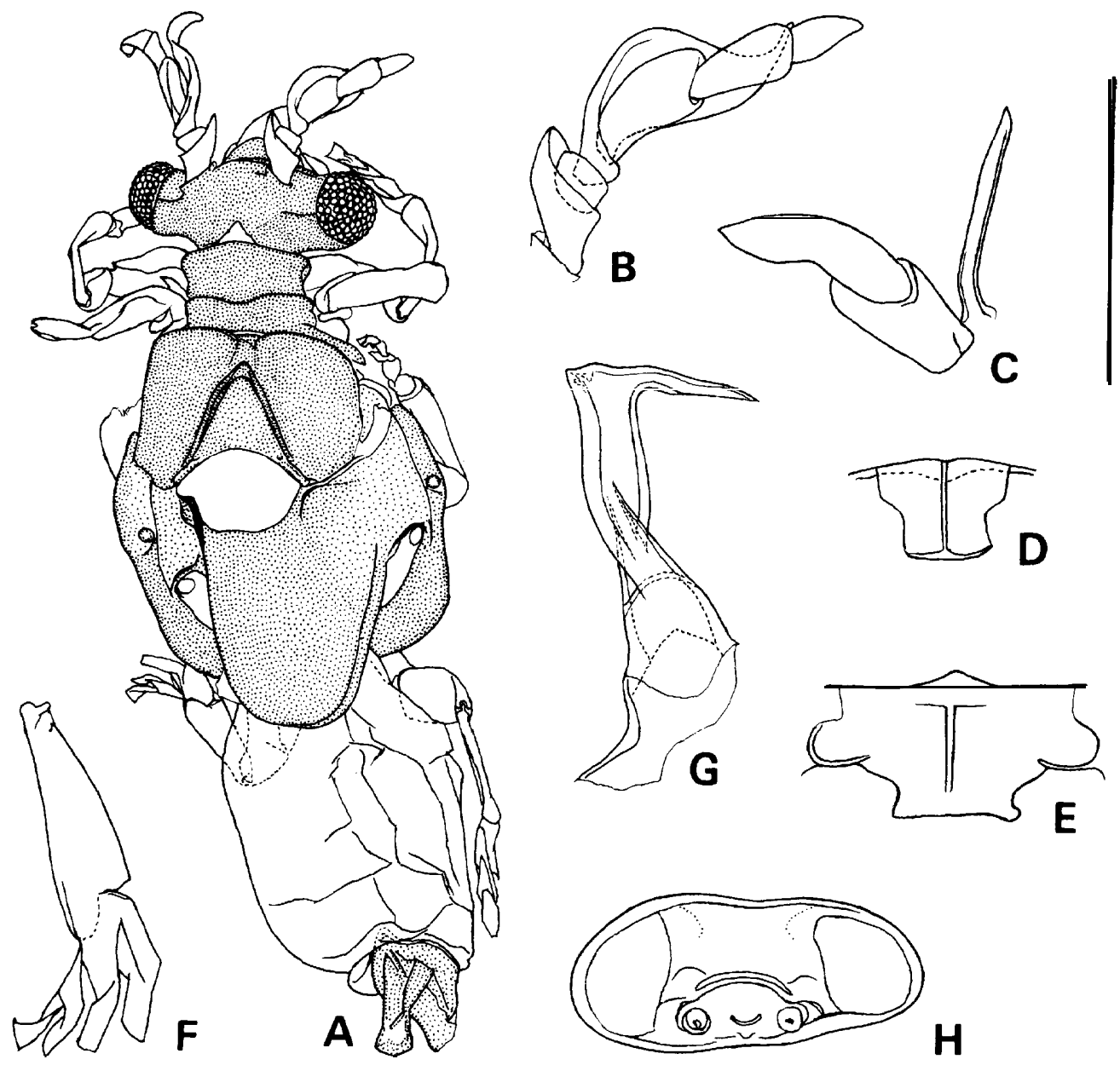

Fig. 21. Stylops yamatonis Kifune et Hirashima, 1985, male.-A, Dorsal aspect ; B, right antenna, dorsal view ; C, left mandible and maxillary palpus, ventral view ; D, prosternum, median portion, ventral view ; E, mesosternum, median portion, ventral view, F, left hind tibia and tarsi, ventral view ; G, aedeagus, left lateral view ; $\mathrm{H}$, cephalotheca, frontal view. Scale, $1 \mathrm{~mm}$ for A \& $\mathrm{H} ; 0.25$ $\mathrm{mm}$ for $\mathrm{G}, 0.5 \mathrm{~mm}$ for others.

smaller in size of cephalothorax, darker in pigmentation, and broader in the posterior expansion of the abdominal pigmented area than those of the type material, but seems to be conspecific with this new species. These differences may be depending on the remoteness of the locality against those of the type specimens.

\section{Description of a Newly Known Male}

Stylops yamatonis Kifune et Hirashima, 1985 
A single male extracted frtm a male of A. (Simandrena) yamato(4R), Nishikawatsu, Matsue, Honshu, 15. iv. 1983 (A. Yoshida), is examined.

Size. Total length of body $3.0 \mathrm{~mm}$; head breadth $0.80 \mathrm{~mm}$; breadths of pro- and metathorax 0.42 and $1.08 \mathrm{~mm}$, respectively ; length of head and thorax together $1.92 \mathrm{~mm}$; radial length of hind wing more than $1.8 \mathrm{~mm}$; length of aedeagus $0.31 \mathrm{~mm}$.

Structure. Head transverse ; frons elliptically protruded ; antennae 6-segmented, 1st segment subconical, 2nd segment short, broader than long, 3rd segment conical, with broad flabellum of which tip surpassing the tip of 5th antennal segment ; 4th segment about two-thirds as broad as flabellum, 5th segment thickening towards tip, a little shorter than 4 th, 6 th segment subtriangular, with blunt tip ; mandibles slender, sword-like ; maxillary palpi 2-segmented, basal segment thick, apical segment lightly bent at the middle point, about two-thirds as thick as basal segment, terminal portion tapering ; eyes hemispherical, composed of numerous facets which are larger on the ventral side ; posterior margin of head slightly concave. Pro- and mesonota short ; metathorax more or less deformed by the mounting procedure ; scutum very small, almost invisible from above ; parascuti subtriangular, their anterior margins rounded ; scutellum triangular, its posterior margin curved inwardly ; postlumbium elliptical ; postscutellum broad, conical, its posterior margin rounded ;proand mesosterna as figured. Hind wings not fully developed ; legs normal. Genital capsule subpentagonal ; proctiger rather long, slightly constricted at near the median portion ; aedeagus comparatively large, with a comparatively long, sharp dorsal process which almost perpendicularly produced from the shaft.

Male cephalotheca (Fig. 21H)

Slightly deformed by the mounting pressure. Longitudinal and transverse lengths 0.50 and 1.14 $\mathrm{mm}$, respectively ; ratio of both lengths $1: 2.28$. Morphological features as figured.

REMARKS ; This male is easily distinguishable from the male of $S$. borealis, which is the sole known male of the genus in Japan, by the smaller size of body, longer antennal flabellum, longer apical segment of maxillary palpus, slenderer proctiger, larger aedeagus and longer dorsal process of aedeagus.

\section{Distributional Records of Known Species}

Among the nine already known species of the Japanese Stylops, the following seven species were obtained from the present material. Each of new hosts and newly recorded prefectures are indicated by the subsequent asterisk in the summarizing clause only. Examined specimens are arranged by their localities from north to south. Because some specimens were labelled with the local place name only, necessary names of the higher rank (prefecture etc.) are supplemented in brackets. In the case of too many specimens available from the same locality, a certain host bees were remained their parasites unextracted. Such materials are enumerated without records of the parasitic positions. 1 de means an empty male puparium.

1. Stylops oblongulus Kifune et Hirashima, 1985

TYPE HOST : Andrena (Andrena) longitibialis Hirashima.

TYPE LOCALITY : Hodosan, Saitama, Honshu.

SPECIMENS EXAMINED : (Host : A. (A.) longitibialis) 1 stylopized female host, Matsuzono, Morioka, Iwate, 24. v. 1980 (Y. Maeta);19(4R), gravid, extracted from a female host, same locality, 28. v. 1980 (Y. Maeta);19 (4R) from a male, Toyotama, [Nerima, Tokyo,] 18. iv. 1949 [(R. Ishikawa)] ; 1 (4L), gravid, from a female, Mt. Nyugasa, Ina, Nagano, 15-17. vii. 1962 (H. Fujii).

REMARKs : Two female parasites (each one from Iwate and Nagano) have more gently curved lateral margins of cephalothorax than those of the type specimen from Saitama and of the female 
from Toyotama, but are not specifically different.

Distribution : Honshu-Iwate', Saitama, Nagano".

2. Stylops truncatoides Kifune et Hirashima, 1985

TYPE HOST : Andrena (Andrena) lapponica shirozui Hirashima.

TYPE LOCALITY : Nukabira, Tokachi, Hokkaido.

Specimens examrned : (Host : A. (A.) lapponica shirozui) 19 (4R) from a female, Sugatami, [Mt. Daisetsu, Hokkaido,] 23. vi. $1967 ; 1$ stylopized female, same locality, 10. vii. 1967 ; 10 e (4L) \& 1 ? (4R) from a female, same locality, 22. vii. $1967 ; 1$; (4R) from a female, Mt. Hakkoda, Aomori, 8. vii. 1958 (R. Ishikawa).

DistRIBUTION : Hokkaido-Ishikari*, Tokachi ; Honshu*-Aomori*.

3. Stylops japonicus Kifune et Hirashima, 1985

TYPE HOST : Andrena (Andrena) benefica Hirashima.

TyPE LOCALiTY : Mt. Hikosan, Fukuoka, Kyushu.

Specimens examined : (Host : A. (A.) benefica) 1 ( (4R) from a male, Dake Spa, Aomori, 4. v. 1960 (M. Takahashi) ; 1 stylopized female, Mori, Koshoku City, [Nagano,] 20. iv. 1961 (Y. Maeta); 1 stylopized female, same locality, 17. iv. 1962 (Y. Maeta);19 (4L) \& $10^{7}$ e (4R) from a female and another stylopized female, Minamiminowa, Ina, Nagano, 6. iv. 1961 (Y. Maeta);3९ๆ (4L, 4L, 4M) each from 3 females and 5 stylopized females, same locality, 7. iv. 1961 (Y. Maeta);2ᄋo (4R, 4R) from 2 males and 6 stylopized males \& 3 stylopized females, same locality, 13. iv. 1961 (Y. Maeta); 1 stylopized female, same locality, 2. v. 1961 (Y. Maeta); 1 stylopized female, same locality, 7. iv. 1962 (Y. Maeta) ; 2 $९$ (4L, 4R) from a female and 5 stylopized males \& 4 stylopized females, same locality, 11. iv. 1962 (Y. Maeta); 1 stylopized female, same locality, 12. iv. 1962 (Y. Maeta); 1 stylopized male \& 1 stylopized female, same locality, 20. iv. 1962 (K. Hara) ; 1 stylopized male, same locality and date (Y. Maeta) ; 1 stylopized female, same locality, 24. iv. 1962 (K. Hara) ;1 (4L) from a male and 4 stylopized males \& 2 stylopized females, same locality, 12. iv. 1963 (Y. Maeta) ; 1 stylopized male \& 2 stylopized females, same locality, 14. iv. 1963 (Y. Maeta); 2 stylopized females, same locality, 17. iv. 1963 (Y. Maeta).

Distribution : Honshu-Aomori*, Nagano*; Kyushu-Fukuoka.

4. Stylops yamatonis Kifune et Hirashima, 1985

TYPE HOST : Andrena (Simandrena) yamato Tadauchi et Hirashima.

TYPE LOCALITY : Miyanojo, Kagoshima, Kyushu.

Specimens eXAmmed : (Host: A. (S.) yamato) 19 (4L) from a female and 2 stylopzied males \& 1 stylopized female, Nagae, Matsue, [Shimane,] 30. iii. 1982 (Y. Maeta).

Distribution : Honshu-Iwate, Shimane* ; Kyushu-Kagoshima.

5. Stylops kaguyae Kifune et Hirashima, 1985

T YPE HOST : Andrena (Micrandrena) kaguya Hirashima.

TYPE LOCALITY : Fukuoka, Kyushu.

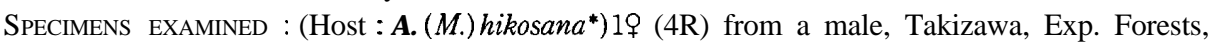
Iwate, 26. iv. 1976 (Y. Maeta \& T. Matsumura) ; 1 stylopized male \& 1 stylopized female, same locality, 17. v. 1976 (Y. Maeta \& T. Matsumura) ; 19 (4R) from a male, Kuriyagawa, Morioka, Iwate, 16. iv. 1975 (Y. Maeta). (Host : A. (M.) komachi*) 1o (4L), gravid, from a female, Miimachi, Kurume, [Fukuoka,] 21. v. 1960 (Y. Maeta). (Host: A. (M.) minutula) 1 stylopized female, Takizawa, Exp. Forests, Iwate, 16. iv. 1976 (Y. Maeta \& T. Matsumura) ; 2 stylopized males \& 1 stylopized female, same locality, 26. iv. 1976 (Y. Maeta \& T. Matsumura) ; 2 stylopized males \& 1 stylopized female, same locality, 7. v. 1976 (Y. Maeta \& T. Matsumura) ; 2 stylopized females, same locality, 14. v. 1976 (Y. Maeta \& T. Matsumura) ; 1 stylopized female, same locality, 26. v. 1976 (Y. Maeta\& T. Matsumura) $; 19(4 \mathrm{M})$, gravid, from a female and a stylopized female, Rifu-cho, Miyagi, 28. v. 1978 
(K. Goukon) ; 1 stylopized female, same locality, 4. v. 1980 (K. Goukon) ; 2 stylopized females, Shosenkyo, Yamanashi, 11. iv. 1963 (Y. Maeta) ;19 (4L) from a female, Takato, Ina, Nagano, 19. v. 1963 (Y. Maeta) ; 10 e (4L) from a female, Nagae, Matsue, [Shimane,] 30. iii. 1982 (Y. Maeta). (Host : A. (M.) kaguya) 2 stylopized males \& 2 stylopized females, Takizawa, Exp. Forests, Iwate, 16. iv. 1976 (Y. Maeta \& T. Matsumura) ; 2 stylopized females, same locality, 26. iv. 1976 (Y. Maeta \& T. Matsumura) ; 1 stylopized male, same locality, 28. iv. 1976 (Y. Maeta \& T. Matsumura) ; 2 stylopized females, same locality, 7. v. 1976 (Y. Maeta \& T. Matsumura) ;1 (4M) from a female, 1 stylopized male, \& other 4 stylopized females, same locality, 13. iv. 1980 (Y. Maeta);2\$o (4L, 4R) from a male, Kuriyagawa, Morioka, Iwate, 15. iv. 1975 (Y.Maeta); 1 stylopized male \& 1 stylopized female, same locality, 16. iv. 1975 (Y. Maeta); 1 stylopized male, same locality, 12. iv. 1980 (Y. Maeta); 1 stylopized female, same locality, 27. iv. 1980 (Y. Maeta); 2 stylopized females, Rifucho, Miyagi, 10. iv. 1977 (K. Goukon) ; 1 stylopized female, same locality, 9. iv. 1978 (K. Goukon) ; 1 stylopized male \& 2 stylopized females, same locality, 5. iv. 1980 (K. Goukon) ; 1 stylopized female, same locality, 19. iv. 1980 (K. Goukon) ;2९९ from 2 females, Shosenkyo, Yamanashi, 1. iv. 1962 (T. Saigusa) ;10̛ e (4R) from a male, another stylopzied male, \& 2 stylopized females, same locality, 6. iv. 1962 (T. Saigusa).

REMARKS : The occurrence of a stylopized komachi with $10^{7}$ empty puparium in Fukuoka was already recorded by Kifune \& Hirashima (1985). A. (M.) hikosana is recorded as a host of this species for the first time.

Distribution : Honshu-Iwate', Miyagi*, Saitama, Yamanashi*, Nagano*, Hyogo, Shimane*, Yamaguchi ; Kyushu-Fukuoka, Kagoshima.

6. Stylops borealis Kifune et Hirashima, 1985

TYPE HOST : Andrena (Taeniandrena) ezoensis Hirashima = A. (T.) ovatula (Kirby).

TYPE LOCAlity : Ashoro, Tokachi, Hokkaido.

Specimens examined : (Host : A. (T.)ovatula) 2 stylopized males \& 2 stylopized females, Hitsujigaoka, Sapporo, [Ishikari, Hokkaido,] 20. vi. 1971 (Y. Maeta); 1 stylopized male, same locality, 23. vi. 1971 (Y.Maeta); 1 stylopized female, same locality, 27. vi. 1971 (Y. Maeta) ; 1 stylopized female, same locality, 9. vii. 1971 (Y. Maeta); 2 stylopized females, same locality, 5. viii. 1971 (Y. Maeta); 1 stylopized female, same locality, 9. viii. 1971 (Y. Maeta); 1 stylopized female, same locality, 21. viii. 1971 (Y.Maeta); 1 stylopized female, same locality, 4. vii. 1972 (Y. Maeta) ; 1 stylopized male \& 8 stylopized females, same locality, 6. vii. 1972 (Y. Maeta) ; 2 stylopized females, same locality, 9. vii. 1972 (Y. Maeta) ; 1 stylopized male, same locality, 23. viii. 1972 (Y. Maeta) ; 1 stylopized male, Soranuma, [Sapporo, Hokkaido,] 12. vi. $1968 ; 2$ $29(4 \mathrm{M}, 4 \mathrm{R})$, gravid, from a female $\&$ another stylopized female, same locality, 12. vii. $1968 ; 10^{\text {\% }}$ (4L) from a male, Kyogoku, Iburi, [Hokkaido,] 11. vi. 1962 (M. Munakata) ;10 , immature, from a male, same locality, 12. vi. 1962 (M. Munakata) ; 10 (4M) from a male, same locality, 27. vi. 1966 (M. Munakata) ; 10 (4R) from a male, Esashi, Hiyama, [Hokkaido,] 15. vi. 1966 (M. Munakata) ;1 stylopized female, Koiwai, Shizukuishi, Iwate, 10. vii. 1968 (Y. Maeta);1 stylopized female, Kuriyagawa, Morioka, Iwate, 23. vi. 1968 (Y. Maeta) ; 1 stylopized female, same locality, 14. vi. 1978 (Y. Maeta).

DistRIBUtion : Hokkaido-Tokachi, Ishikari*, Iburi*, Hiyama* ; Honshu-Iwate'.

7. Stylops valerianae Kifune et Hirashima, 1985

TYPE HOST : Andrena (Holandrena) valeriana Hirashima.

TYPE LOCALITY : Ashoromura, Tokachi, Hokkaido.

Specimens examined : (Host · A. (H.) valeriana) $299(4 \mathrm{~L}, 4 \mathrm{R})$, gravid, from 2 females, Hitsujigaoka, Sapporo, 26. viii. 1971 (Y. Maeta); lde (3L) \& 1 \% (3R) from a female and $10^{\text {' e }}$ (3R) \& 19 (4R) from another female, Kuriyagawa, Morioka, Iwate, 9. viii. 1964 (Y. Maeta).

Distribution : Hokkaido-Tokachi, Ishikari* ; Honshu*-Iwate*.

The result of the present study is summarized in Table 1 . 
Table 1. A list of the stylopized Andrena examined.

\begin{tabular}{|c|c|c|}
\hline (Subgenus) Host Species & $\begin{array}{c}\text { No. of } \\
\text { Specimens } \\
\text { examined }\end{array}$ & $\begin{array}{l}\text { Stylopid para- } \\
\text { site in Japan }\end{array}$ \\
\hline (Andrena) nawai Cockerell & 3 & collinus sp. nov. \\
\hline (A.) longitibialis Hirashima & 4 & oblongulus $\mathrm{K}$. et $\mathrm{H} .^{*}$ \\
\hline (A.) lapponica shirozui Hirashima & & truncatoides $\mathrm{K}$. et $\mathrm{H}$. \\
\hline (A.) benejica Hirashima & 53 & japonicus K. et $\mathrm{H}$. \\
\hline (A.) aburana Hirashima & 3 & aburanae sp. nov. \\
\hline (Hoplandrena) dentata Smith & 1 & dentatae sp. nov. \\
\hline (H.) sachalinensis $Y$ asumatsu & & aino sp. nov. \\
\hline (Gymnandrena) watasei Cockerell & 6 & orientis sp. nov. \\
\hline (G.) parathoracica Hirashima & 2 & hirashimai sp. nov. \\
\hline (Simandrena) yamato Tadauchi et Hirashima & 5 & yamatonis $\mathrm{K}$. et $\mathrm{H}$. \\
\hline (S.) opacifovea opacifovea Hirashima & 4 & izumoensis sp. nov. \\
\hline (S.) nippon Tadauchi et Hirashima & & nipponicus sp. nov. \\
\hline (Mircandrena) hikosana Hirashima & & kaguyae $\mathrm{K}$. et $\mathrm{H}$. \\
\hline (M.) komachi Hirashima & 1 & kaguyae $\mathrm{K}$. et $\mathrm{H}$. \\
\hline (M.) minutula (Kirby) & 18 & kaguyae $\mathbf{K}$. et $\mathrm{H}$. \\
\hline (M.) kaguya Hirashima & 33 & kaguyae $\mathrm{K}$. et $\mathrm{H}$. \\
\hline (Oreomelissa) mitakensis Hirashima & 3 & montanus sp. nov. \\
\hline (Taeniandrena) ovatula (Kirby)' & 34 & borealis $\mathrm{K}$. et $\mathrm{H}$. \\
\hline (Mitsukuriella) japonica (Smith) & 3 & subcircularis sp. nov. \\
\hline (M.) fukaii Cockerell & 14 & subcircularis sp. nov. \\
\hline (Holandrena) valeriana Hirashima & 4 & valerianae $\mathrm{K}$. et $\mathrm{H}$. \\
\hline $21 \mathrm{spp}$. & 201 & 17 spp. \\
\hline
\end{tabular}

${ }^{*} \mathrm{~K}$. et $\mathrm{H}$.=Kifune et Hirashima (1985).

${ }^{+}$Formerly ezoensis Hirashima.

\section{Acknowledgements}

We are much indebted to Dr. 0. Tadauchi (Kyushu University) for the identifications and taxonomic informations on the host bees. We also wish to thank the following persons who kindly gave us the valuable stylopized bee specimens. Drs. T. Shirozu, R. Ishikawa, and M. Takahashi, Prof. T. Saigusa, Messrs. H. Fujii, K. Goukon, K. Hara, T. Kitamura, S. Koike, T. Matsumura, M. Munakata, T. Nomura, K. Oshima, Y. Sasaki, and A. Yoshida.

\section{References}

Bohart, R. M., 1941. A revision of the Strepsiptera with special reference to the species of North America. Univ. Calif. Publ. Ent., 7 : 91-159.

Kifune, T., \& Y. Hirashima, 1985. Nine new species of the genus Stylops (Strepsiptera : Stylopidae) parasitic on the genus Andrena (Hymenoptera: Andrenidae) of Japan (Studies on the Japanese Strepsiptera X). Esakia, (23) : 45-57.

Kinzelbach, R. K., 1978. Fächerflügler (Strepsiptera). Tierw.Deutschl., (65) : 1-166.

Luna de Carvalho, E., 1974. Contribuição para o estudo dos Stylops de Peninsula ibérica (Streps. Stylopidae). Eos, $48:$ 301-365.

Pierce, W. D., 1909. A monographic revision of the twisted winged insects comprising the order 
Strepsiptera Kirby. U.S.natn.Mus., Bull., (66) : I-XII, 1-232, 15 pls.

Tadauchi, O., Y. Hirashima, \& T. Matsumura, 1987. Synopsis of Andrena (Andrena) of Japan

(Hymenoptera, Andrenidae). Part II. J.Fac.Agr., Kyushu Univ., 31 : 37-54. 